\title{
Article \\ A Theoretical Survey of the UV-Visible Spectra of Axially and Peripherally Substituted Boron Subphthalocyanines ${ }^{\dagger}$
}

\author{
Al Mokhtar Lamsabhi (D), M. Merced Montero-Campillo (D), Otilia Mó (i) and Manuel Yáñez * \\ Departamento de Química, Módulo 13, Facultad de Ciencias and Institute for Advanced Research in Chemical \\ Sciences (IAdChem), Universidad Autónoma de Madrid, 28049 Madrid, Spain; \\ mokhtar.lamsabhi@uam.es (A.M.L.); mm.montero@uam.es (M.M.M.-C.); otilia.mo@uam.es (O.M.) \\ * Correspondence: manuel.yanez@uam.es \\ + This paper is dedicated to Prof. Karlheinz Schwarz on the occasion of his 80th birthday.
}

\begin{abstract}
The UV-visible spectra of a series of subphthalocyanines (SubPcs) characterized by three different axial substituents $\left(\mathrm{A}_{\mathrm{n}}\right)$ in combination with $\mathrm{H}, \mathrm{F}, \mathrm{NO}_{2}, \mathrm{SO}_{2} \mathrm{H}$ and $\mathrm{SO}_{2} \mathrm{CH}_{3}$ peripheral substituents $\left(\mathrm{R}_{\mathrm{i}}\right)$ were predicted and analyzed by means of time-dependent DFT calculations, including chloroform as a solvent. In this analysis, we paid particular attention to the $Q$ band, which remained almost unchanged regardless of the nature of the axial substituent. For the same axial substituent, changes in the $\mathrm{Q}$ band were also rather small when hydrogens at the periphery were replaced by $\mathrm{R}_{1}=\mathrm{SO}_{2} \mathrm{H}$ and $\mathrm{R}_{1}=\mathrm{R}_{2}=\mathrm{SO}_{2} \mathrm{H}$. However, the shifting of the $Q$ band was almost 10 times larger when $R_{1}=N_{2}$ and $R_{1}=R_{2}=N O_{2}$ due to the participation of this substituent in the $\pi$ SubPc cloud. In most cases, the characteristics of the spectra can be explained considering only the transitions involving the HOMO-1, HOMO, LUMO and LUMO + 1 orbitals, where the Q band can be decomposed into two main contributions, leading to charge separation. Only for $\operatorname{SubPc}\left(\mathrm{A}_{3}, \mathrm{~F}, \mathrm{~F}, \mathrm{H}\right)$ would one of the two contributions from the deepest orbital involved not lead to charge transfer. For this latter case, the HOMO-2 orbital must also be taken into account. In summary, the results obtained with the analysis of the MO indicate that the studied SubPcs are appropriate for photochemical devices.
\end{abstract}

Montero-Campillo, M.M.; Mó, O.; Yáñez, M. A Theoretical Survey of the UV-Visible Spectra of Axially and Peripherally Substituted Boron Subphthalocyanines. Computation 2022, 10, 14. https://doi.org/ 10.3390/computation10020014 Academic Editors: Henry Chermette and Giuseppe Zollo

Received: 20 December 2021

Accepted: 14 January 2022

Published: 18 January 2022

Publisher's Note: MDPI stays neutral with regard to jurisdictional claims in published maps and institutional affiliations.

Copyright: (c) 2022 by the authors. Licensee MDPI, Basel, Switzerland. This article is an open access article distributed under the terms and conditions of the Creative Commons Attribution (CC BY) license (https:// creativecommons.org/licenses/by/ $4.0 /)$.

Keywords: subphthalocyanines; UV-visible spectra; axial substituents; peripheral substituents; time-dependent DFT

\section{Introduction}

Theoretical and computational chemistry has played a very important role in the development of chemistry since the late 20th century to the present, providing tools to understand experiments and ways to predict the behavior of many different systems. In this sense, the work developed by K. Schwarz is a good example. Suffice it to mention his contributions to the development of functionals to achieve a good description of solid-state materials [1], the WIEN code being a paradigmatic example of this potentiality [2]. In particular, computational chemistry has been equally useful for shedding light on the mechanisms behind the photoactivity of various organic compounds, such as subphthalocyanines (SubPcs) [3].

SubPcs are a typical porphyrin species (see Scheme 1) discovered in the last half of the 20th century [4]. They present a non-planar, $14 \pi$-electron macrocyclic ring that accommodates a B(III) ion at its binding core.

The most frequently used method to incorporate macrocycles for the axial functionalization of SubPcs is substitution at its central boron atom, with the added advantage that the $\pi$-conjugated macrocycle maintains its electronic characteristics [5]. This synthetic versatility is behind a very rich and interesting SubPc metallosupramolecular chemistry. It also allows for the preparation of energy donors or energy acceptors based on SubPcs, which lends them ideal properties as photoactive entities through their excited states. SubPcs typically display intense Q-band transitions in the 550-650 $\mathrm{nm}$ region [5]. More 
importantly, their excellent light-harvesting ability, with high extinction coefficients, can be modulated through the nature of the peripheral substituents, which are important factors regarding SubPc photostability [5]. Interestingly, due to the fact that SubPcs have a coneshaped aromatic structure, the effect of peripheral substituents can be intricate. It has been found [6] that the profile of the absorption spectra depends on whether both substituents are on the same or different sides of the molecular cone.

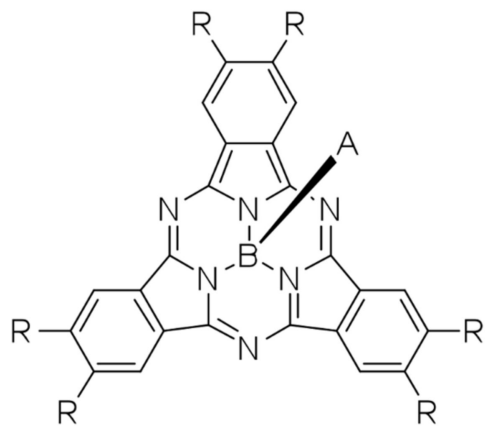

Scheme 1. Subphthalocyanines (SubPcs).

An adequate combination with axial substituents allows for even more fine tuning of SubPcs with excellent properties for photochemical devices, such as a lower tendency to aggregate [5]. A paradigmatic example of photochemical tuning is dodecafluorosubphthalocyanine, an excellent electron-acceptor unit. When this unit is covalently bound to a triphenylamine moiety, which is an excellent electron donor, the resulting derivative becomes an efficient electron donor-acceptor system [3]. Further relevant examples of what can be achieved through axial functionalization have been reported. For instance, SubPcs with axial alkoxo substituents form optically active inclusion complexes with $\beta$ cyclodextrin [7], SubPcs dyads with an axial ferrocenyl substituent can exhibit efficient fluorescence quenching [8], and axial aryl-substituted SubPcs exhibit very similar photoluminescence behavior regardless of the nature of the substituent at the para position of the aryl group [9]. SubPcs with a ferrocenylethynyl unit in the axial position exhibit interesting optical and redox properties [10], and rylene-annulated SubPcs also present an excellent photovoltaic performance [11]. SubPcs with ferrocenecarboxylic acid as an axial ligand also combine very interesting redox and photophysical properties, as the first reversible oxidations take place at the axial ligand, while the second oxidation is located in the SubPc ring [12]. Very recently, SubPc hydride derivatives with a high reactivity have been prepared for the first time as hydroboration reagents of aldehydes [13]. Another interesting case is that of the axial-phenoxylated SubPcs, which show spectroscopical properties for the singly reduced and singly oxidized species that can be tuned with changes in axial and peripheral substituents [14], whereas the reversibility of the redox reactions seems to be correlated with some characteristics of the boron-to-axial ligand bond [14]. In regard to larger axial substituents, it has been shown that a novel series of SubPcs with macrocycle axial substitution show interesting behavior as fluorescent probes and photodynamic therapy agents, their biological activity being determined by the nature of the macrocycle [15]. Finally, it was found that SubPc polymers have similar photoluminescence characteristics to those of SubPc units, although the emission of the polymer depends on the excitation wavelength [16].

In our group, we have previously explored, on theoretical grounds, the UV-visible spectra of SubPcs, in which the central boron atom was replaced by aluminum or gallium by using time-dependent DFT calculations, including chloroform as a solvent [17]. This replacement led to a redshift of the $Q$ band, which is not very dependent on either the nature of the peripheral substituents or the nature of the central atom. More recently, the behavior of boron chloride SubPcs with a core-expanded six-membered ring was theoretically investigated, and the compound with three six-membered rings was found to be a promising organic solar cell donor material due to its small exciton binding energy [18]. 
As indicated above, there are many studies on SubPcs that include a variety of peripheral substituents, but the amount of information is very scarce when dealing with axial substituents. The aim of the present study is to determine the effects on the photochemical behavior of SubPcs of three different axial substituents (An) combined with some of the most common peripheral $R_{1}, R_{2}$ and $R_{3}$ substituents, as shown in Scheme 2.

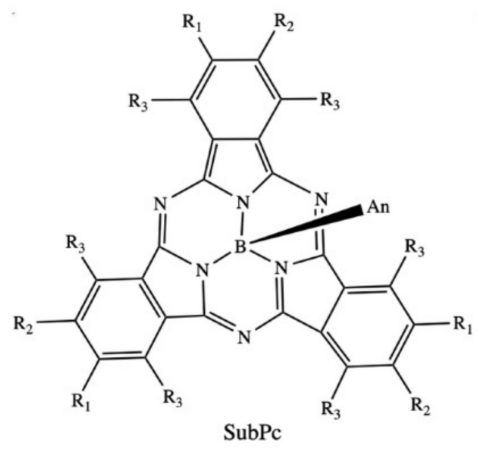

$\mathrm{SubPc}$

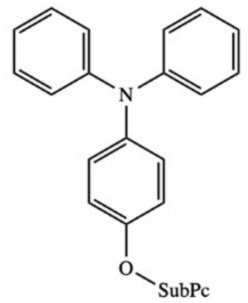

A1

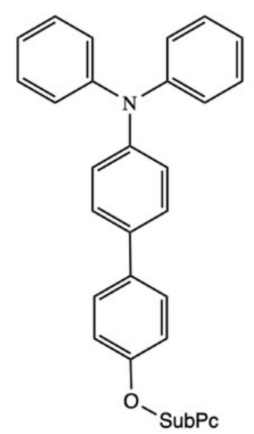

A2

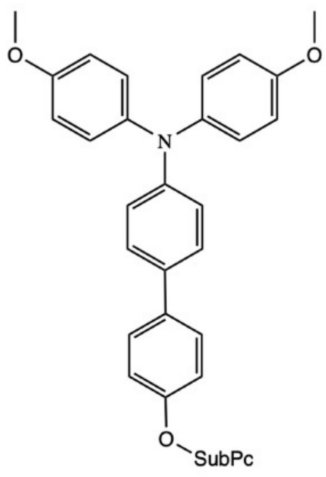

A3

$\mathrm{R}_{1}: \mathrm{H}, \mathrm{SO}_{2} \mathrm{H}, \mathrm{SO}_{2} \mathrm{CH}_{3}, \mathrm{NO}_{2}, \mathrm{~F}$

$\mathbf{R}_{2}: \mathrm{H}, \mathrm{SO}_{2} \mathrm{CH}_{3}, \mathrm{NO}_{2}, \mathrm{~F}$

$\mathbf{R}_{3}: H, F$

Scheme 2. SubPcs $\left(A n, R_{1}, R_{2}, R_{3}\right)$ envisaged in this study, where $A n=\{A 1, A 2, A 3\}$ are the axial substituents and $R_{1}, R_{2}$ and $R_{3}$ are the peripheral substituents.

\section{Computational Details}

The geometries of all SubPcs were fully optimized in the ground state at the B3LYP/6$31 G(d)$ computational level. The stationary points found were assessed as local minima of the corresponding potential energy surface through the calculation of their harmonic frequencies at the same level of accuracy. To obtain the corresponding UV-Vis absorption spectra, we employed a linear response time-dependent density functional theory (TD-DFT) formalism, using the optimized geometries mentioned above for the ground state. Accordingly, the excitation energies (both in vacuum and using chloroform as a solvent), the oscillator strengths $f$ and the dominant electronic transitions correspond to vertical excitations. These values for all these magnitudes were obtained by single-point calculations at the B3LYP/6-31 + G(d,p) level.

Since all the experimental data are usually obtained in chloroform and not in the gas phase, solvent effects were evaluated by means of the polarizable continuum model (PCM) as implemented in Gaussian 09 programs. More precisely, solvent shifts of the excitation bands were obtained by the nonequilibrium implementation of the PCM through single-point calculations on equilibrium geometries obtained in vacuum. This methodology has been shown to be suitable to reproduce the experimental values in systems similar to those considered in the present publication $[3,6,17]$.

The absorption spectra were plotted using the SWizard program package, represented as a sum of Gaussian functions that follows Equation (1):

$$
\varepsilon(\omega)=2.174 * 10^{8} \sum_{i} \frac{f_{i}}{\Delta_{1 / 2}} \exp \left(-2.773 \frac{\left(\omega-\omega_{i}\right)^{2}}{\Delta_{1 / 2}^{2}}\right)
$$

where $\varepsilon$ is the molar absorbance $\left(\mathrm{mol}^{-1} \mathrm{~cm}^{-1} \mathrm{~L}^{-1}\right)$, which depends on the computed excitation energies, $\omega_{i}$ (in $\mathrm{cm}^{-1}$ ), and their corresponding oscillator strengths, $f_{i}$. The halfweight bandwidth is represented by $\Delta^{2}{ }_{1 / 2}$, and it is assumed to be constant $\left(1200 \mathrm{~cm}^{-1}\right)$. 


\section{Results and Discussion}

For the remainder of this paper, we use the notation $\operatorname{SubPc}\left(A n, R_{1}, R_{2}, R_{3}\right)$ to identify the different SubPcs included in our study (see Scheme 2). For the largest A2 and A3 axial substituents, calculations with $\mathrm{SO}_{2} \mathrm{H}, \mathrm{SO}_{2} \mathrm{CH}_{3}$ and $\mathrm{NO}_{2}$ as peripheral substituents may become prohibitively expensive. Hence, for A3 only, the parent compound and the all-fluor-substituted derivative are considered, whereas for A2, we add to these two cases the derivative in which $\mathrm{R}_{1}=\mathrm{NO}_{2}$. The optimized geometries are reported in Table S1 of Supplementary Materials. Although we do not discuss them in detail, it is important to emphasize that all of them are nonplanar, a basic structural characteristic of these compounds. A good measure of the pyramidalization of the structure is the sum of the bond angles around the boron atom, with a value close to 312 degrees. This value is practically independent of the nature of the peripheral and the axial substituents.

\subsection{Calculated UV-Visible Spectra}

Since comparisons between the simulated and experimental spectra for the particular case of SubPcs are almost inexistent, we thought it was important, as the first step of our survey, to check the performance of our theoretical scheme. For this purpose, we compare in Figure S1 of Supplementary Materials the available experimental spectrum for $\operatorname{SubPc}(\mathrm{A} 2, \mathrm{~F}, \mathrm{~F}, \mathrm{~F})[3]$ with our calculated one. The agreement is rather satisfactory, with the maximum displacement being $40 \mathrm{~nm}$ for the B band and, most importantly, $10 \mathrm{~nm}$ smaller for the Q band.

Although the calculated spectra for the SubPcs to be discussed always correspond to those in $\mathrm{CHCl}_{3}$ solution, we considered it of interest to know whether the solvent effect is important. To check this aspect, we calculated the UV-visible spectra for $\operatorname{SubPc}(\mathrm{A} 2, \mathrm{H}, \mathrm{H}, \mathrm{H})$ in both the gas phase and in $\mathrm{CHCl}_{3}$ solution. As shown in Figure S2 of Supplementary Materials, the solvent leads to a rather small shifting $(\sim 10 \mathrm{~nm})$ of the $\mathrm{Q}$ band to lower frequencies, whereas the effects on the $\mathrm{B}$ band are almost negligible.

As the agreement with the experimental data and the effect of the solvent are revised, we now focus our attention on the analysis of the impact of the axial and peripheral substituents on the optical properties. Figure 1 shows the effect of replacing the axial substituents in two different structures, namely, $\operatorname{SubPc}(\mathrm{An}, \mathrm{H}, \mathrm{H}, \mathrm{H})$ and $\operatorname{SubPc}(\mathrm{An}, \mathrm{F}, \mathrm{F}, \mathrm{F})$. The first important and conspicuous fact is that, in all cases, the $Q$ band is not sensitive to the nature of the axial substituent. Instead, the peripheral substituents have a clear effect: in the spectra shown in the $(\operatorname{SubPc}(\mathrm{An}, \mathrm{H}, \mathrm{H}, \mathrm{H}))$ case, the maximum for the $\mathrm{Q}$ band is at $516 \mathrm{~nm}$, which is shifted to $528 \mathrm{~nm}$ for $(\mathrm{SubPc}(\mathrm{An}, \mathrm{F}, \mathrm{F}, \mathrm{F}))$. The situation is different as far as the B band is concerned. When there are no peripheral substituents, the maxima appear at $310 \mathrm{~nm}$ independently of the nature of the axial substituent, though for A2 and A3, a second secondary maximum is predicted at longer wavelengths (350 and $364 \mathrm{~nm}$, respectively). The situation changes slightly when all the peripheral substituents are F atoms. Now, the maximum of the B band appears at a shorter wavelength for the A1 axial substituent $(320 \mathrm{~nm})$ than for A2 and A3 (359 and $369 \mathrm{~nm}$, respectively).

Figure 2 shows a comparison between $\operatorname{SubPc}(\mathrm{A} 1, \mathrm{H}, \mathrm{H}, \mathrm{H}), \operatorname{SubPc}\left(\mathrm{A} 1, \mathrm{SO}_{2} \mathrm{H}, \mathrm{H}, \mathrm{H}\right)$ and $\mathrm{SubPc}\left(\mathrm{A} 1, \mathrm{SO}_{2} \mathrm{H}, \mathrm{SO}_{2} \mathrm{H}, \mathrm{H}\right)$, where the axial substituent remains unchanged. As evidenced by the picture, the position of the $B$ and $Q$ bands is affected very little by the presence of the sulfonate groups. The maximum of the B band shifts from 316 to $323 \mathrm{~nm}$ in the first case and to $328 \mathrm{~nm}$ in the second, whereas the shiftings for the Q band from 520 to 524 and $528 \mathrm{~nm}$, respectively, though some changes in their intensity are also observed. 

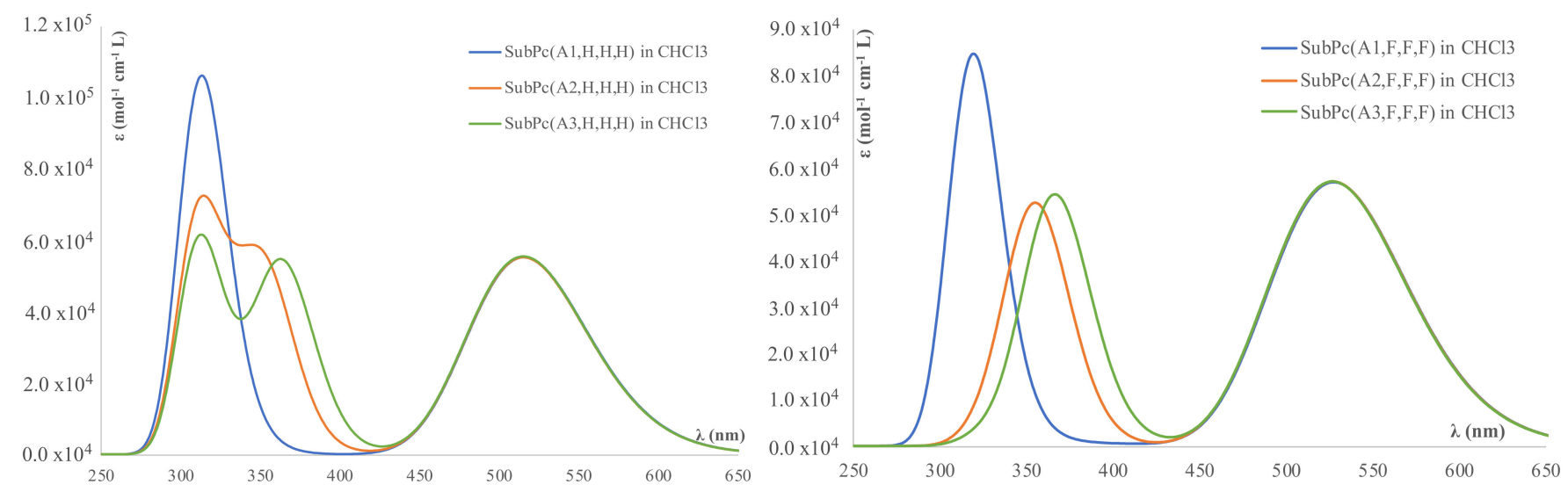

Figure 1. Calculated UV-visible spectra for $\operatorname{SubPc}\left(A n, R_{1}, R_{2}, R_{3}\right)$, with $n=1,2,3 ; R_{1}=R_{2}=R_{3}=H$, F, dissolved in $\mathrm{CHCl}_{3}$.

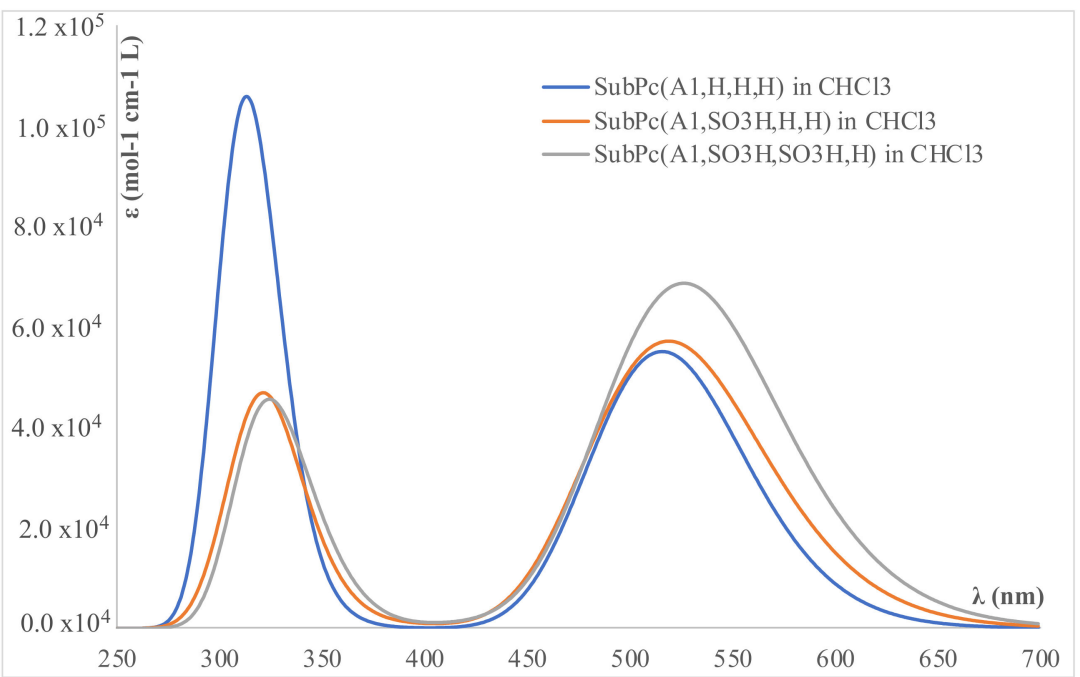

Figure 2. Calculated UV-visible spectra for $\operatorname{SubPc}\left(A 1, \mathrm{R}_{1}, \mathrm{R}_{2}, \mathrm{R}_{3}\right)$ with $\mathrm{R}_{1}=\mathrm{R}_{2}=\mathrm{R}_{3}=\mathrm{H} ; \mathrm{R}_{1}=\mathrm{SO}_{2} \mathrm{H}$, $\mathrm{R}_{2}=\mathrm{R}_{3}=\mathrm{H} ; \mathrm{R}_{1}=\mathrm{R}_{2}=\mathrm{SO}_{2} \mathrm{H}, \mathrm{R}_{3}=\mathrm{H}$, dissolved in $\mathrm{CHCl}_{3}$.

Figure 3 shows the situation when the peripheral substituents are nitro groups rather than $\mathrm{SO}_{2} \mathrm{H}$. In this case, it can be observed that the shifting of the $\mathrm{Q}$ band is now significantly larger (from 519 to $576 \mathrm{~nm}$ ), but, again, it is rather similar for $R_{1}=N_{2}$ and $R_{1}=R_{2}=N_{2}$. The effects on the $\mathrm{B}$ band are also more significant than those observed for $\mathrm{SO}_{2} \mathrm{H}$ substituents, in both the intensity of the band and its position. When only $\mathrm{R}_{1}$ substitutions take place, the B band splits into two peaks of much lower intensity and shifts from 314 to 345 and $427 \mathrm{~nm}$. When $R_{2}$ substitutions also take place, only a shoulder at about $433 \mathrm{~nm}$ remains. This is very likely due to the ability of the $\mathrm{NO}_{2}$ groups to participate through their electron lone pair into the aromatic cloud of the SubPc six-membered rings, which does not occur for substituents such as $\mathrm{F}$ and $\mathrm{SO}_{2} \mathrm{H}$. We come back to this point in the next section.

We saw above that, when the axial substituent is A1, the replacement of the substitution of $\mathrm{R}_{1}$ by $\mathrm{NO}_{2}$ splits the $\mathrm{B}$ band into two sub-bands. Figure 4 shows that a similar splitting is observed for axial substituent A2, though the intensity of the first sub-band is much higher than for A1. 


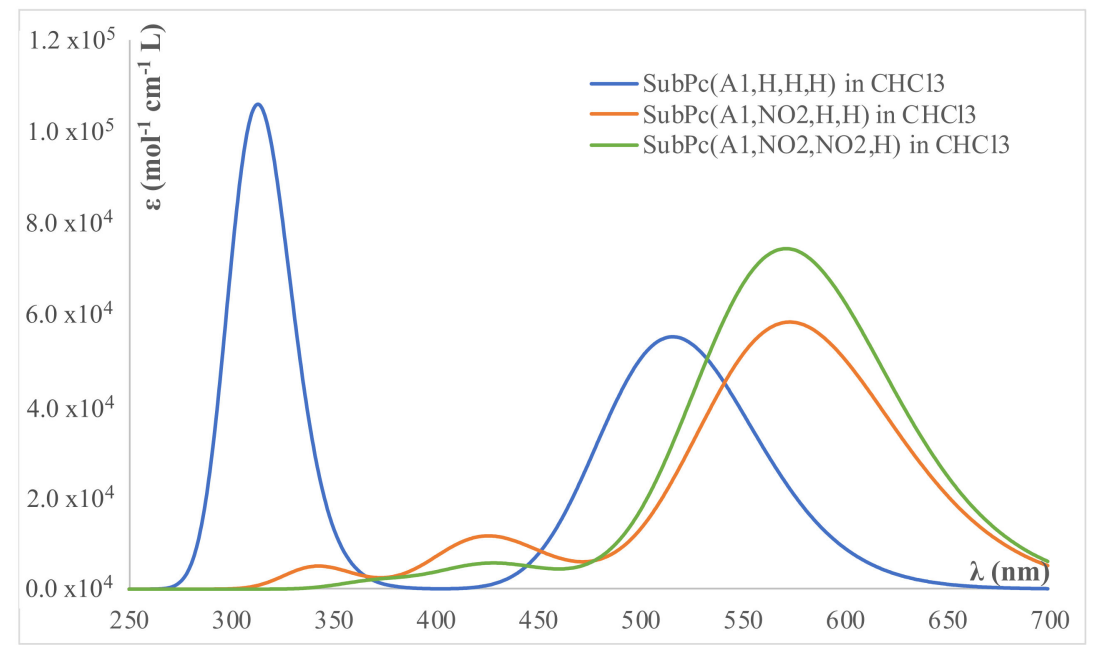

Figure 3. Calculated UV-visible spectra for SubPc $\left(A 1, R_{1}, R_{2}, R_{3}\right)$, with $R_{1}=R_{2}=R_{3}=H ; R_{1}=N_{2}$, $\mathrm{R}_{2}=\mathrm{R}_{3}=\mathrm{H} ; \mathrm{R}_{1}=\mathrm{R}_{2}=\mathrm{NO}_{2}, \mathrm{R}_{3}=\mathrm{H}$, dissolved in $\mathrm{CHCl}_{3}$.

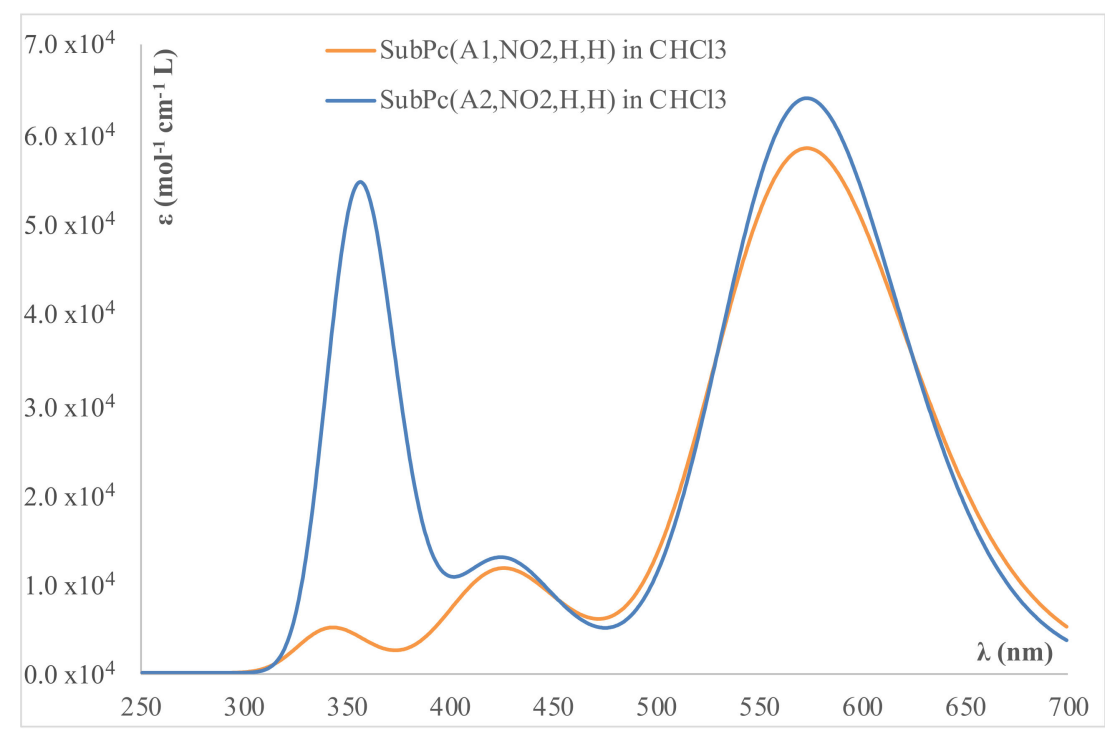

Figure 4. Comparison between the calculated UV-visible spectra of $\operatorname{SubPc}\left(\mathrm{A} 1, \mathrm{NO}_{2}, \mathrm{H}, \mathrm{H}\right)$ and $\operatorname{SubPc}\left(\mathrm{A} 1, \mathrm{NO}_{2}, \mathrm{H}, \mathrm{H}\right)$.

\subsection{MO Analysis}

The calculated spectra obtained for the SubPcs under analysis can be rationalized through the use of the well-known four-orbital model of Martin Gouterman, who, back in the 1960s, described the spectra of porphyrins [19] and proposed that the characteristics of the $\mathrm{Q}$ band observed at about $550 \mathrm{~nm}$ for these compounds could be related to the properties of the two top filled and two lowest empty $\pi$ orbitals involved in the weak excitation to the first excited state $(\mathrm{S} 0 \rightarrow \mathrm{S} 1)$. Two years later, this assumption was consistent with rather simple molecular orbital calculations [20], showing, indeed, that the $Q$ band could be associated with transitions involving the HOMO-1, HOMO, LUMO and LUMO + 1 orbitals. The rest of the absorptions of the spectra that form the Soret or B band at lower wavelengths (around $400 \mathrm{~nm}$ ) are associated with S0 $\rightarrow$ S2 electronic excitations. The same model was also successfully used to rationalize the $Q$ bands of subporphyrins [21], subporphyrazines and SubPcs $[6,17,22-25]$, as well as Be-SubPcs [26] complexes. As explained below, the results show that this model is also valid for the transitions observed in our set, but it needs to be expanded in some specific cases to include the HOMO-2 orbital. 
In Table 1, we summarize the most relevant information for the $Q$ band for the species investigated in solution. Similar information in vacuum is provided in Table S2 of Supplementary Materials.

Table 1. Q-band $\left(\lambda_{\max }\right)$ excitation energies in chloroform, oscillator strengths $f$ and dominant electronic transitions for the SubPcs included in this study ${ }^{\mathrm{a}}$.

\begin{tabular}{|c|c|c|c|c|c|c|c|}
\hline An & $\mathbf{R}_{1}$ & $\mathbf{R}_{2}$ & $\mathbf{R}_{3}$ & $\operatorname{lmax}(e V)$ & $\mathrm{nm}$ & $f$ & Main Configuration \\
\hline \multirow[t]{2}{*}{ A1 } & $\mathrm{H}$ & $\mathrm{H}$ & $\mathrm{H}$ & 2.40 & 516.5 & 0.4107 & $\mathrm{H}-1 \rightarrow \mathrm{L}+1(+87 \%)$ \\
\hline & & & & 2.41 & 515.5 & 0.4403 & $\mathrm{H}-1 \rightarrow \mathrm{L}+2(+87 \%)$ \\
\hline \multirow[t]{2}{*}{$\mathrm{A} 1$} & $\mathrm{~F}$ & $\mathrm{~F}$ & $\mathrm{~F}$ & 2.35 & 527.9 & 0.4230 & $\mathrm{H}-1 \rightarrow \mathrm{L}+1(+99 \%)$ \\
\hline & & & & 2.36 & 526.3 & 0.4534 & $\mathrm{H}-1 \rightarrow \mathrm{L}+2(+99 \%)$ \\
\hline \multirow[t]{2}{*}{ A1 } & $\mathrm{SO}_{2} \mathrm{H}$ & $\mathrm{H}$ & $\mathrm{H}$ & 2.38 & 520.8 & 0.4749 & $\mathrm{H}-1 \rightarrow \mathrm{L}+\mathrm{O}(+97 \%)$ \\
\hline & & & & 2.39 & 519.2 & 0.5087 & $\mathrm{H}-1 \rightarrow \mathrm{L}+1(+97 \%)$ \\
\hline \multirow[t]{2}{*}{ A1 } & $\mathrm{SO}_{2} \mathrm{CH}_{3}$ & $\mathrm{SO}_{2} \mathrm{CH}_{3}$ & $\mathrm{H}$ & 2.35 & 527.2 & 0.5735 & $\mathrm{H}-1 \rightarrow \mathrm{L}+\mathrm{O}(+97 \%)$ \\
\hline & & & & 2.36 & 525.6 & 0.6106 & $\mathrm{H}-1 \rightarrow \mathrm{L}+1(+97 \%)$ \\
\hline \multirow[t]{2}{*}{$\mathrm{A} 1$} & $\mathrm{SO}_{2} \mathrm{CH}_{3}$ & $\mathrm{H}$ & $\mathrm{H}$ & 2.39 & 519.8 & 0.4762 & $\mathrm{H}-1 \rightarrow \mathrm{L}+\mathrm{O}(+97 \%)$ \\
\hline & & & & 2.39 & 518.1 & 0.5091 & $\mathrm{H}-1 \rightarrow \mathrm{L}+1(+97 \%)$ \\
\hline \multirow[t]{2}{*}{$\mathrm{A} 1$} & $\mathrm{NO}_{2}$ & $\mathrm{H}$ & $\mathrm{H}$ & 2.16 & 573.7 & 0.4387 & $\mathrm{H}-1 \rightarrow \mathrm{L}+\mathrm{O}(+98 \%)$ \\
\hline & & & & 2.17 & 572.2 & 0.4614 & $\mathrm{H}-1 \rightarrow \mathrm{L}+1(+97 \%)$ \\
\hline \multirow[t]{2}{*}{$\mathrm{A} 1$} & $\mathrm{NO}_{2}$ & $\mathrm{NO}_{2}$ & $\mathrm{H}$ & 2.16 & 572.7 & 0.5569 & $\mathrm{H}-1 \rightarrow \mathrm{L}+0(+98 \%)$ \\
\hline & & & & 2.18 & 569.9 & 0.588 & $\mathrm{H}-1 \rightarrow \mathrm{L}+1(+97 \%)$ \\
\hline \multirow[t]{2}{*}{$\mathrm{A} 2$} & $\mathrm{H}$ & $\mathrm{H}$ & $\mathrm{H}$ & 2.4 & 515.9 & 0.4108 & $\mathrm{H}-1 \rightarrow \mathrm{L}+\mathrm{O}(+97 \%)$ \\
\hline & & & & 2.41 & 514.8 & 0.4432 & $\mathrm{H}-1 \rightarrow \mathrm{L}+1(+97 \%)$ \\
\hline \multirow[t]{2}{*}{ A2 } & $\mathrm{NO}_{2}$ & $\mathrm{H}$ & $\mathrm{H}$ & 2.16 & 573.6 & 0.3952 & $\mathrm{H}-1 \rightarrow \mathrm{L}+\mathrm{O}(+86 \%)$ \\
\hline & & & & 2.17 & 572.6 & 0.4249 & $\mathrm{H}-1 \rightarrow \mathrm{L}+1(+85 \%)$ \\
\hline \multirow[t]{2}{*}{ A2 } & $\mathrm{F}$ & $\mathrm{F}$ & $\mathrm{F}$ & 2.35 & 527.5 & 0.4215 & $\mathrm{H}-1 \rightarrow \mathrm{L}+0(+97 \%)$ \\
\hline & & & & 2.36 & 526.5 & 0.449 & $\mathrm{H}-1 \rightarrow \mathrm{L}+1(+96 \%)$ \\
\hline \multirow[t]{2}{*}{ A3 } & $\mathrm{H}$ & $\mathrm{H}$ & $\mathrm{H}$ & 2.4 & 515.8 & 0.4102 & $\mathrm{H}-1 \rightarrow \mathrm{L}+0(+97 \%)$ \\
\hline & & & & 2.41 & 514.8 & 0.4452 & $\mathrm{H}-1 \rightarrow \mathrm{L}+1(+97 \%)$ \\
\hline \multirow[t]{3}{*}{ A3 } & $\mathrm{F}$ & $\mathrm{F}$ & $\mathrm{F}$ & 2.34 & 529.7 & 0.1861 & $\begin{array}{c}\mathrm{H}-2 \rightarrow \mathrm{L}+0(+55 \%) \\
\mathrm{H}-1 \rightarrow \mathrm{L}+1(39 \%)\end{array}$ \\
\hline & & & & 2.35 & 527.9 & 0.3587 & $\begin{array}{l}\mathrm{H}-1 \rightarrow \mathrm{L}+0(+82 \%) \\
\mathrm{H}-2 \rightarrow \mathrm{L}+1(+13 \%)\end{array}$ \\
\hline & & & & 2.37 & 523.2 & 0.2743 & $\mathrm{H}-1 \rightarrow \mathrm{L}+1(+56 \%)$ \\
\hline
\end{tabular}

${ }^{\mathrm{a}} \mathrm{H}-2, \mathrm{H}-1, \mathrm{~L}+\mathrm{0}, \mathrm{L}+1$ stands for HOMO-2, HOMO-1, LUMO and LUMO + 1, respectively.

The results in Table 1 show that, for all the systems investigated, there are two main transitions responsible for the $\mathrm{Q}$ band at very similar wavelengths. The first one, $\mathrm{Q}_{1}$, is associated with the HOMO- $\rightarrow$ LUMO transition, and the second one, $\mathrm{Q}_{2}$, is associated with the HOMO-1 $\rightarrow$ LUMO + 1 transition, which indicates that, in practically all the systems investigated, the LUMO and LUMO + 1 orbitals are almost degenerate. It can also be observed that $\operatorname{SubPc}(\mathrm{A} 3, \mathrm{~F}, \mathrm{~F}, \mathrm{~F})$ is the only exception to this general behavior, as we discuss later.

The transitions mentioned above as being responsible for the $\mathrm{Q}$ band are illustrated in Figure 5 for the particular case of $\operatorname{SubPc}(\mathrm{A} 2, \mathrm{H}, \mathrm{H}, \mathrm{H})$, which is taken as a suitable example, but this same scheme is also observed for $\operatorname{SubPc}(\mathrm{A} 1, \mathrm{H}, \mathrm{H}, \mathrm{H}), \operatorname{SubPc}\left(\mathrm{A} 1, \mathrm{NO}_{2}, \mathrm{H}, \mathrm{H}\right)$, $\operatorname{SubPc}\left(\mathrm{A} 1, \mathrm{NO}_{2}, \mathrm{NO}_{2}, \mathrm{H}\right), \operatorname{SubPc}\left(\mathrm{A} 1, \mathrm{SO}_{2} \mathrm{H}, \mathrm{H}, \mathrm{H}\right), \operatorname{SubPc}\left(\mathrm{A} 1, \mathrm{SO}_{2} \mathrm{CH}_{3}, \mathrm{H}, \mathrm{H}\right), \operatorname{SubPc}\left(\mathrm{A} 1, \mathrm{SO}_{2} \mathrm{CH}_{3}\right.$, $\left.\mathrm{SO}_{2} \mathrm{CH}_{3}, \mathrm{H}\right)$, SubPc $\left(\mathrm{A} 2, \mathrm{NO}_{2}, \mathrm{H}, \mathrm{H}\right)$ and $\operatorname{SubPc}(\mathrm{A} 2, \mathrm{~F}, \mathrm{~F}, \mathrm{~F})$. Very importantly, this figure clearly illustrates that, for all these systems, the HOMO-1 orbital is located at the axial substituent, whereas both the LUMO and LUMO + 1 orbitals are localized at the SubPc moiety, with the obvious consequence that the $\mathrm{Q}$ band is associated with a charge transfer phenomenon from the axial substituent toward the SubPc moiety. 


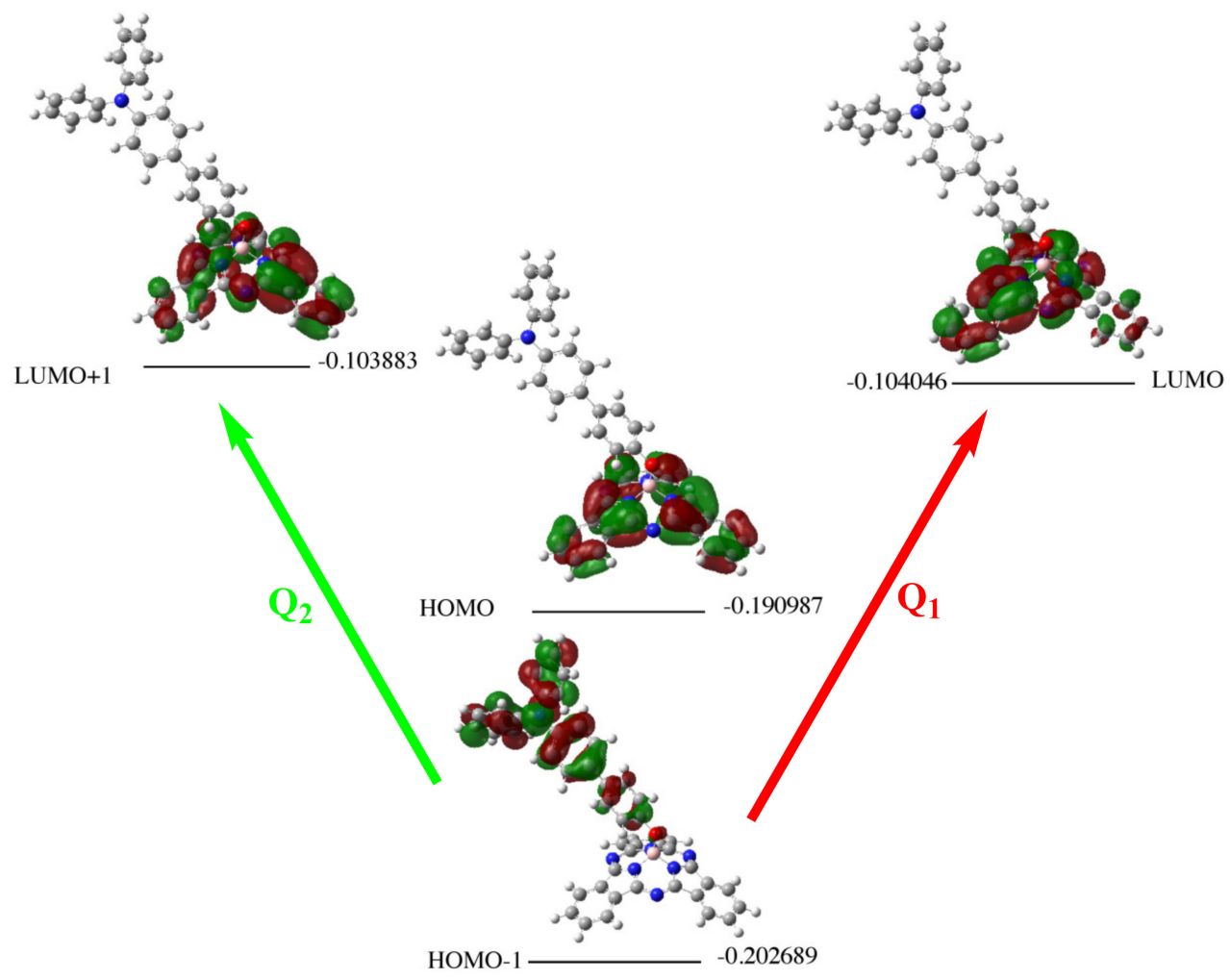

Figure 5. MO diagram showing, for $\operatorname{SubPc}(\mathrm{A} 2, \mathrm{H}, \mathrm{H}, \mathrm{H})$, the main transitions $\mathrm{Q}_{1}$ and $\mathrm{Q}_{2}$ contributing to the $\mathrm{Q}$ band, which are accompanied by a charge transfer phenomenon. Molecular orbital energies are in hartrees.

The fact that the LUMO and the LUMO + 1 orbitals are localized at the SubPc moiety also permits the explanation as to why, as already mentioned in the previous section, the shifting of the $Q$ band is much larger for $R_{1}=N_{2}$ and $R_{1}=R_{2}=N_{2}$ with respect to the parent compound $\left(\mathrm{R}_{1}=\mathrm{R}_{2}=\mathrm{H}\right)$ than it is for $\mathrm{R}_{1}=\mathrm{SO}_{2} \mathrm{H}$ and $\mathrm{R}_{1}=\mathrm{R}_{2}=\mathrm{SO}_{2} \mathrm{H}$. Indeed, as illustrated in Figure 5, the two main components of the $\mathrm{Q}$ band correspond to transitions that reach these two empty orbitals, whose energies change significantly when the $\mathrm{H}$ atoms are replaced by $\mathrm{NO}_{2}$ groups. These substituents, as shown in Figure S3 of Supplementary Materials, conjugate with the aromatic $\pi$-system through their $\mathrm{N}$ lone pair. This interaction cannot occur when $\mathrm{R}_{1}=\mathrm{H}$ or $\mathrm{R}_{1}=\mathrm{SO}_{2} \mathrm{H}$, as evidenced in Figure $\mathrm{S} 3$, as these groups participate neither in the LUMO nor in the LUMO + 1 orbitals.

Rather interestingly, when $\mathrm{A} 2$ is replaced by $\mathrm{A} 3$ as an axial substituent, the dominant transitions are still HOMO- $1 \rightarrow$ LUMO for the $\mathrm{Q}_{1}$ component and HOMO- $1 \rightarrow$ LUMO +1 for the $Q_{2}$ one. However, the presence of the methoxy group at the axial substituent stabilizes the orbital located at the SubPc subunit, which becomes the HOMO-1 orbital, whereas the orbital localized at the axial substituent becomes the HOMO orbital (see Figure 6). As a consequence, the $\mathrm{Q}$ absorption band of $\operatorname{SubPc}(\mathrm{A} 3, \mathrm{H}, \mathrm{H}, \mathrm{H})$ is not accompanied by a charge transfer phenomenon, because the two $Q_{1}$ and $Q_{2}$ components involve electron densities that are always localized at the SubPc subunit.

The situation becomes somewhat more complicated when moving from the parent compound to the derivative, in which all peripheral substituents are $\mathrm{F}$ atoms. In this case, some transitions have their origin not only in the HOMO-1 orbital but also in the HOMO-2 orbital, so the $\mathrm{Q}$ band has three rather than two components (see Figure 7). 


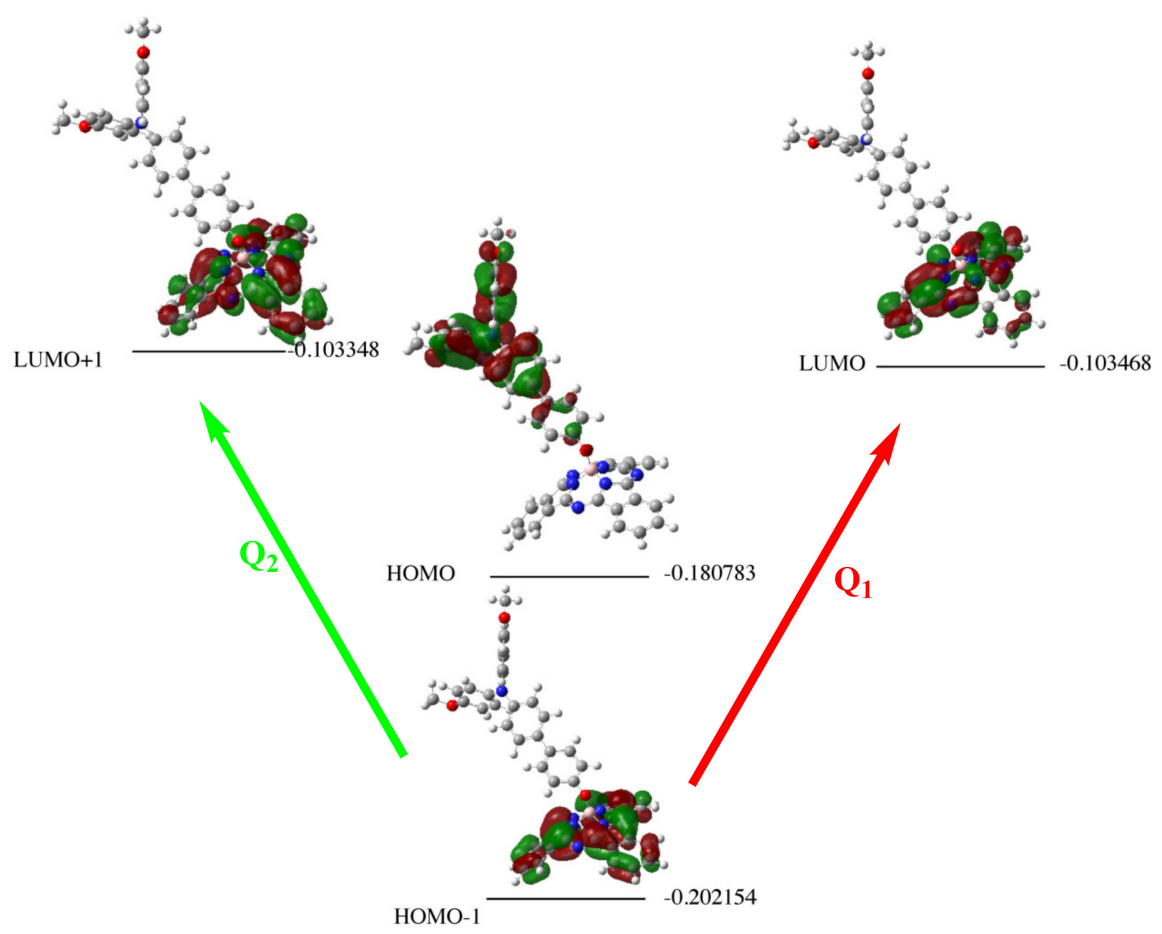

Figure 6. $\mathrm{MO}$ diagram of $\operatorname{SubPc}(\mathrm{A} 3, \mathrm{H}, \mathrm{H}, \mathrm{H})$, showing the main transitions $\mathrm{Q}_{1}$ and $\mathrm{Q}_{2}$ contributing to the $\mathrm{Q}$ band, which is not accompanied by a charge transfer phenomenon. Molecular orbital energies are in hartrees.

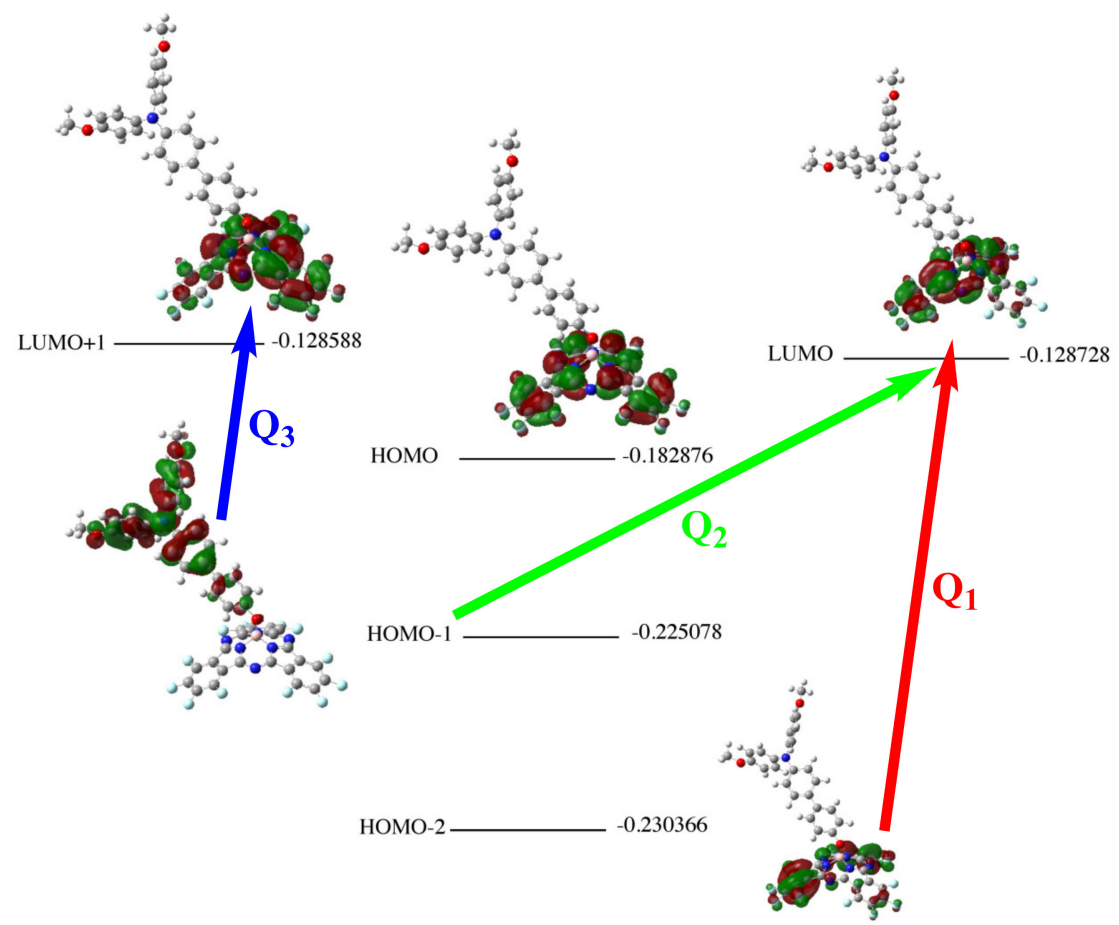

Figure 7. MO diagram showing, for $\operatorname{SubPc}(\mathrm{A} 3, \mathrm{~F}, \mathrm{~F}, \mathrm{H})$, the main transitions $\mathrm{Q}_{1}, \mathrm{Q}_{2}$ and $\mathrm{Q}_{3}$ contributing to the $\mathrm{Q}$ band. The $\mathrm{Q}_{2}$ and $\mathrm{Q}_{3}$ components are accompanied by a charge transfer phenomenon. Molecular orbital energies are in hartrees.

More specifically, the following transitions are detected:

$\mathrm{Q}_{1}$ component: HOMO-2 $\rightarrow \mathrm{LUMO}(55 \%) ; \mathrm{HOMO}-1 \rightarrow \mathrm{LUMO}+1(39 \%)$ 


$$
\begin{aligned}
& \mathrm{Q}_{2} \text { component: HOMO-1 } \rightarrow \mathrm{LUMO}(82 \%) ; \mathrm{HOMO}-2 \rightarrow \mathrm{LUMO}+1(13 \%) \\
& \mathrm{Q}_{3} \text { component: HOMO-1 } \rightarrow \mathrm{LUMO}+1(56 \%) ; \mathrm{HOMO}-2 \rightarrow \mathrm{LUMO}(41 \%)
\end{aligned}
$$

Hence, globally, the $\mathrm{Q}$ band is accompanied by a charge transfer phenomenon but only through the $\mathrm{Q}_{2}$ and $\mathrm{Q}_{3}$ components.

\section{Conclusions}

The electronic spectra of SubPc are typically characterized by two main absorption bands: one typically in the visible region, called the $\mathrm{Q}$ band, and another at lower wavelengths, named the B band or the Soret band. In our theoretical survey, we found that the $\mathrm{Q}$ band is not sensitive to axial replacement for SubPcs with H or F peripheral substituents. The situation is not very different when it is the axial substituent that remains unchanged (A1) and peripheral hydrogens that are replaced by $\mathrm{R}_{1}=\mathrm{SO}_{2} \mathrm{H}$ and $\mathrm{R}_{1}=\mathrm{R}_{2}=\mathrm{SO}_{2} \mathrm{H}$. Indeed, in this case, the $Q$ band is only slightly shifted by 4 and $8 \mathrm{~nm}$. The shiftings when $\mathrm{R}_{1}=\mathrm{NO}_{2}$ and $R_{1}=R_{2}=N_{2}$ are rather similar but almost 10 times larger than those observed for $\mathrm{SO}_{2} \mathrm{H}$.

In general, the effects on the characteristics of the B band are more apparent. For instance, the $\mathrm{Q}$ band is not altered when all peripheral substituents are fluorine atoms and when the axial substituent A1 is replaced by A2 or A3, but the B band is shifted $40 \mathrm{~nm}$ to longer wavelengths. Similarly, the B band splits into two peaks of much lower intensity and shifts from 31 and $113 \mathrm{~nm}$ to longer wavelengths when $R_{1}=\mathrm{H}$ is replaced by $R_{1}=N_{2}$, keeping the A1 axial substituent unchanged. These effects are slightly stronger when both $\mathrm{R}_{1}$ and $\mathrm{R}_{2}$ are replaced.

In most cases, the characteristics of the spectra can be explained by considering only the transitions involving the HOMO-1, HOMO, LUMO and LUMO +1 orbitals, as in the well-known Gouterman model [19]. Nevertheless, when the axial substituent is A3, we found that the spectra can only be accounted for if transitions from the HOMO-2 orbital are also taken into account.

From a global perspective, the results collected in this work and those previously reported for other substitution patterns indicate that the optical properties of boron SubPcs regarding the $\mathrm{Q}$ band are very robust toward axial and peripheral substitutions.

Supplementary Materials: The following supporting information can be downloaded at: https: / / www.mdpi.com/article/10.3390/computation10020014/s1, Figure S1: Comparison between the calculated and the experimental UV-Vis spectra for SubPc (A2,F,F,F) dissolved in $\mathrm{CHCl}_{3}$; Figure S2: Comparison between the UV-Vis spectrum of $\operatorname{SubPc}(\mathrm{A} 2, \mathrm{H}, \mathrm{H}, \mathrm{H})$ in the gas-phase and in $\mathrm{CHCl} 3$ solution; Figure S3: LUMO of SubPc $(\mathrm{A} 1, \mathrm{H}, \mathrm{H}, \mathrm{H})$, SubPc $\left(\mathrm{A} 1, \mathrm{SO}_{2} \mathrm{CH}_{3}, \mathrm{SO}_{2} \mathrm{CH}_{3}, \mathrm{H}\right)$ and SubPc $\left(\mathrm{A} 1, \mathrm{NO}_{2}, \mathrm{H}, \mathrm{H}\right)$; Table S1: Cartesian coordinates; Table S2: Q-Band excitation energies in vacuum, oscillator strengths and dominant electronic transitions.

Author Contributions: Conceptualization, M.Y. and A.M.L.; original draft preparation, M.Y.; writing, review and editing, M.M.M.-C., O.M., M.Y. and A.M.L.; formal analysis, M.M.M.-C., O.M., M.Y. and A.M.L.; methodology, M.M.M.-C. and A.M.L.; investigation, M.M.M.-C., O.M., M.Y. and A.M.L.; project administration, O.M.; funding acquisition, O.M. and M.Y. All authors have read and agreed to the published version of the manuscript.

Funding: This work was carried out with financial support from the projects PGC2018-094644-B-C21 and PID2019-110091GB-I00 funded by the Ministerio de Ciencia, Innovación y Universidades of Spain (MICIN/AEI) and the PRIES-CM project Ref: Y2020/EMT-6290 from the Comunidad Autónoma de Madrid.

Institutional Review Board Statement: Not applicable.

Acknowledgments: Thanks are also given to the Centro de Computación Científica of the UAM (CCC-UAM) for the generous allocation of computer time and for their continued technical support.

Conflicts of Interest: The authors declare no conflict of interest. 


\section{References}

1. Blaha, P.; Schwarz, K.; Sorantin, P.; Trickey, S.B. Full-potential, linearized augmented plane-wave programs for crystalline systems. Comput. Phys. Commun. 1990, 59, 399-415. [CrossRef]

2. IAEA Wien Automatic System Planning (WASP) Package A Computer Code for Power Generating System Expansion Planning Version WASP-IV; Computer Manual Series no. 16; International Atomic Energy Agency: Vienna, Austria, 2001.

3. Medina, A.S.; Claessens, C.G.; Rahman, G.M.A.; Lamsabhi, A.M.; Mó, O.; Yáñez, M.; Guldi, D.M.; Torres, T. Accelerating charge transfer in a triphenylamine-subphthalocyanine donor-acceptor system. Chem. Commun. 2008, 15, 1759-1761. [CrossRef] [PubMed]

4. Meller, A.; Ossko, A. Triisindolo 1,2,3-cd-1' ,2',3'-gh-1", ,2", $3^{\prime \prime}-\mathrm{kl}$ 2,3a,5,6a,8,9a,9b-Hena-azaboraphenalene. Monatsh. Chem. 1972, 103, 150-153. [CrossRef]

5. Claessens, C.G.; González-Rodríguez, D.; Rodríguez-Morgade, M.S.; Medina, A.; Torres, T. Subphthalocyanines, Subporphyrazines, and Subporphyrins: Singular Nonplanar Aromatic Systems. Chem. Rev. 2014, 114, 2192-2277. [CrossRef] [PubMed]

6. Lamsabhi, A.; Yáñez, M.; Mó, O.; Trujillo, C.; Blanco, F.; Alkorta, I.; Elguero, J.; Caballero, E.; Rodríguez-Morgade, M.S.; Claessens, C.G.; et al. TDDFT study of the UV-vis spectra of subporphyrazines and subphthalocyanines. J. Porphyr. Phthalocyanines 2011, 15, 1220-1230. [CrossRef]

7. Adachi, K.; Watarai, H. Site-selective formation of optically active inclusion complexes of alkoxo-subphthalocyanines with beta-cyclodextrin at the toluene/water interface. Chem. Eur. J. 2006, 12, 4249-4260. [CrossRef] [PubMed]

8. Solntsev, P.V.; Spurgin, K.L.; Sabin, J.R.; Heikal, A.A.; Nemykin, V.N. Photoinduced Charge Transfer in Short-Distance Ferrocenylsubphthalocyanine Dyads. Inorg. Chem. 2012, 51, 6537-6547. [CrossRef]

9. Bonnier, C.; Josey, D.S.; Bender, T.P. Aryl-Substituted Boron Subphthalocyanines and their Application in Organic Photovoltaics. Austral. J. Chem. 2015, 68, 1750-1758. [CrossRef]

10. Muñoz, A.V.; Gotfredsen, H.; Jevric, M.; Kadziola, A.; Hammerich, O.; Nielsen, M.B. Synthesis and Properties of Subphthalocyanine-Tetracyanobutadiene-Ferrocene Triads. J. Org. Chem. 2018, 83, 2227-2234. [CrossRef]

11. Huang, T.D.; Chen, H.; Feng, J.J.; Zhang, A.D.; Jiang, W.; He, F.; Wang, Z.H. Rylene Annulated Subphthalocyanine: A Promising Cone-Shaped Non-Fullerene Acceptor for Organic Solar Cells. Acs Mater. Lett. 2019, 1, 404-409. [CrossRef]

12. Swarts, P.J.; Conradie, J. Redox and Photophysical Properties of Four Subphthalocyanines Containing Ferrocenylcarboxylic Acid as Axial Ligands. Inorg. Chem. 2020, 59, 7444-7452. [CrossRef]

13. Tejerina, L.; Labella, J.; Martínez-Fernández, L.; Corral, I.; Martínez-Diaz, M.V.; Torres, T. Subphthalocyaninato Boron (III) Hydride: Synthesis, Structure and Reactivity. Chem. Eur. J. 2021, 27, 12058-12062. [CrossRef]

14. Sampson, K.L.; Jiang, X.Q.; Bukuroshi, E.; Dovijarski, A.; Raboui, H.; Bender, T.P.; Kadish, K.M. A Comprehensive Scope of Peripheral and Axial Substituent Effect on the Spectroelectrochemistry of Boron Subphthalocyanines. J. Phys. Chem. A 2018, 122, 4414-4424. [CrossRef] [PubMed]

15. van de Winckel, E.; Mascaraque, M.; Zamarron, A.; de la Fuente, A.J.; Torres, T.; de la Escosura, A. Dual Role of Subphthalocyanine Dyes for Optical Imaging and Therapy of Cancer. Adv. Funct. Mater. 2018, 28, 1705938. [CrossRef]

16. Lessard, B.H.; Sampson, K.L.; Plint, T.; Bender, T.P. Boron subphthalocyanine polymers: Avoiding the small molecule side product and exploring their use in organic light-emitting diodes. J. Polym. Sci. A 2015, 53, 1996-2006. [CrossRef]

17. Montero-Campillo, M.M.; Lamsabhi, A.M.; Mó, O.; Yáñez, M. UV/Vis Spectra of Subporphyrazines and Subphthalocyanines with Aluminum and Gallium: A Time-Dependent DFT Study. Chemphyschem 2013, 14, 915-922. [CrossRef] [PubMed]

18. Peng, S.P.; Zheng, S.H. A computational investigation on core-expanded subphthalocyanines. Int. J. Quant. Chem. 2019, 119, e25942. [CrossRef]

19. Gouterman, M. Spectra of porphyrins. J. Mol. Spect. 1961, 6, 138-163. [CrossRef]

20. Gouterman, M.; Wagnière, G.H.; Snyder, L.C. Spectra of porphyrins: Part II. Four orbital model. J. Mol. Spect. 1963, 11, 108-127. [CrossRef]

21. Takeuchi, Y.; Matsuda, A.; Kobayashi, N. Synthesis and characterization of meso-triarylsubporphyrins. J. Am. Chem. Soc. 2007, 129, 8271-8281. [CrossRef]

22. Shimizu, S.; Yamazaki, Y.; Kobayashi, N. Tetrathiafulvalene-Annulated Subphthalocyanines. Chem. Eur. J. 2013, 19, 7324-7327. [CrossRef]

23. Liang, X.; Shimizu, S.; Kobayashi, N. Sizeable red-shift of absorption and fluorescence of subporphyrazine induced by peripheral push and pull substitution. Chem. Commun. 2014, 50, 13781-13784. [CrossRef]

24. Liu, Q.; Shimizu, S.; Kobayashi, N. Cyclophanes Containing Bowl-Shaped Aromatic Chromophores: Three Isomers of anti- 2.2 (1,4)Subphthalocyaninophane. Angew. Chem. Int. Ed. 2015, 54, 5187-5191. [CrossRef] [PubMed]

25. Esteso, V.; Calio, L.; Espinos, H.; Lavarda, G.; Torres, T.; Feist, J.; García-Vidal, F.J.; Bottari, G.; Míguez, H. Light-Harvesting Properties of a Subphthalocyanine Solar Absorber Coupled to an Optical Cavity. Sol. Rrl 2021, 5, 2100308. [CrossRef]

26. Montero-Campillo, M.M.; Lamsabhi, A.; Mó, O.; Yáñez, M. Photochemical Behavior of Beryllium Complexes with Subporphyrazines and Subphthalocyanines. J. Phys. Chem. A 2016, 120, 4845-4852. [CrossRef] [PubMed] 